\title{
Immunosenescence in Humans: Changes to the Aged T Lymphocyte Population in Response to Persistent Cytomegalovirus Infection
}

\author{
Taylor-Robinson $\mathrm{AW}^{*}$ and Chapman J
}

School of Medical \& Applied Sciences, Central Queensland University, Rockhampton, QLD, Australia

${ }^{*}$ Corresponding author: Taylor-Robinson AW, School of Medical \& Applied Sciences, Central Queensland University, Bruce Highway, Rockhampton, QLD, Australia 4702, Tel: 61749232008, E-mail: a.taylorrobinson@cqu.edu.au

Citation: Taylor-Robinson AW, Chapman J (2015) Immunosenescence in Humans: Changes to the Aged T Lymphocyte Population in Response to Persistent Cytomegalovirus Infection. J Immunol Infect Dis 2(2): 204. doi: 10.15744/2394-6512.1.205

Received Date: August 03, 2015 Accepted Date: October 28, 2015 Published Date: October 30, 2015

\begin{abstract}
Immunosenescence describes the decrease in immune function with advancing age, a phenomenon that is associated with changes in the $\mathrm{B}$ and $\mathrm{T}$ lymphocyte populations. $\mathrm{CD} 8^{+} \mathrm{T}$ cells display the most dramatic phenotypical and functional changes within the $\mathrm{T}$ cell compartment whereby the cohorts of effector and memory $\mathrm{T}$ cells expand while the total population and diversity of naive $\mathrm{T}$ cells both decline. The cause of immunosenescence is unknown; however, the accumulation of antigen-specific T cells, in particular cytomegalovirus (CMV)-specific T cells, may be a contributing factor. CMV is a beta human herpes virus that infects an extensive section of the global human population in which it may produce a lifelong, latent infection. This stimulates a highly immunogenic response that comprises a significant proportion of $\mathrm{T}$ cells that display a high specificity to CMV. It is postulated that this massive $\mathrm{T}$ cell inflation and subsequent exhaustion renders the T cell population senescent, reducing the immune system's ability to combat pathogens as humans age. This review considers fundamental alterations in the immune system in the elderly, focusing on those changes within the $\mathrm{CD} 8^{+} \mathrm{T}$ cell population, and assesses the contribution of chronic CMV infection to immunosenescence. We propose that memory $\mathrm{T}$ cell inflation of CMV-infected individuals and ageing influence the functional and proliferative properties of human CMV-specific T cells, making them less efficient at controlling CMV reactivation.
\end{abstract}

Keywords: Immunosenescence; T Lymphocyte; Cytomegalovirus; Infection; Ageing

\section{Introduction}

The twentieth century and the first years of the new millennium have witnessed a profound increase in ageing of the human population as a consequence of reduced birth rates coupled with an increasing lifespan. The World Health Organization reports that the proportion of elderly individuals, defined as aged $60+$ years, will rise to $22 \%$ of the world population by the year 2050 [1]. This statistic highlights the importance of understanding the relationship between the aged immune system and disease-causing pathogens to which an ageing population may be exposed. The alterations that occur to the immune system in the elderly resulting from persistent viral infection require detailed examination. Here, the impact of chronic cytomegalovirus (CMV) infection on an ageing individual's immunity, and subsequent $\mathrm{T}$ lymphocyte responses to viral stimulation, are discussed. Other persistent viral infections, such as with Epstein-Barr virus, human herpes viruses, or Torque teno virus, may cause similar effects on their host's immune response but which to date are less well defined [2].

The dynamic changes that occur to the aged immune system are collectively termed 'immunosenescence' [3-5]. Pawelec et al. (2010) define immunosenescence as "the impairment in immunity as a result of age-associated changes in function in a variety of cells: it is a phenomenon of decreased function, involving changes to both innate and adaptive immunity and a dysbalance between the two arms" [6]. This brings about a continuous adaptation of the immune system as a result of the degenerative alterations that occur over time [6,7]. The complex changes that remodel the aged immune system are poorly understood as not all immune compartments age in an identical manner [8]. This deterioration of immune function leads increasingly to the elderly being susceptible to infections, latent viral reactivation and reduced vaccine effectiveness [9-11].

The pervasiveness of infectious diseases may severely affect the quality of life of an elderly person. The incidence of viral disease as a cause of death among the elderly has risen in recent years in Australia, representative of developed countries, highlighting the aged immune system's decline in functionality and the impact this has on morbidity and mortality [12]. Alterations of the immune system are considered a natural process during ageing but it is evident that persistent viral infections have severe consequences due to their ability to manipulate to their advantage the host immune system [13]. The factors and mechanisms involved in remodelling the immune response are diverse and it is for this reason that understanding the pathogenic alterations of immune functions caused by persistent viral infections may help to explain different manifestations of the general ageing process, including the development of immunosenescence [14]. 


\section{The Immune System and Persistent Viral Infection}

The effects of immunosenescence cause alterations to both innate and adaptive immunity [6]. The evolution of the innate immune system occurred early in the history of multicellular organisms. Innate immunity involves soluble factors that are essential for the detection of exogenous antigens to ensure either the elimination of pathogens or their containment until activation of the adaptive immune system [15]. The dysfunction of the innate immune system involves multiple cell types and correlates with aberrant outcomes following infection, leading to the development of chronic inflammation and many diseases associated with the elderly $[15,16]$. Activation of the innate cellular repertoire by interaction with viruses evokes a strong $\gamma \delta \mathrm{T}$ cell response. In addition, alterations in the natural killer (NK) memory cell profile are seen in response to antigen stimulation [17-19]. The outcome of these changes is well documented; however, the mechanisms by which they occur are poorly understood [16]. Therefore, additional research is needed to elucidate how ageing affects the innate immune system $[16,20]$. In contrast, studies in both humans and in mouse models have provided insight into the influences of ageing on the adaptive immune system. Found solely in vertebrates, adaptive immunity produces an antigen-specific immune response that may take up to several days to elicit. It consists of humoral and cell-mediated arms, orchestrated by B lymphocytes and T lymphocytes, respectively, in which each clone expresses cell surface receptors of a single specificity [21]. This discussion focuses on the adaptive immune system, centring on the cellular response to viral stimulation and considers how ageing and persistent infection by CMV together influence T cell programming, resulting in immune dysregulation [22].

\section{The Adaptive Immune System}

Activation of adaptive immunity is characterised by the production in large quantities of diverse cells that are specific for a broad selection of antigens. While this would appear to be an inefficient, energy-intensive process, this approach conveys selective advantages for cells to reach maturity. As with the innate immune system, adaptive immunity is associated with immunosenescence resulting in degeneration of immune function. Upon antigenic challenge through infection or vaccination, specific clones are selected for expansion from the cell repertoire and memory cells are produced; however, this successful means of response may become compromised in people over 50 years of age [23]. Changes with age in the adaptive immune response have been noted most in the $\mathrm{T}$ cell population. It is proposed that the long-time proliferation of naive $\mathrm{T}$ cells results in cell-intrinsic dysfunction and a reduced clonal naive $\mathrm{T}$ cell population, as seen in elderly subjects, consequently limiting the immune system's ability to respond to a range of antigens [24-26]. The impairment of immunity has been difficult to determine in the elderly who often have an increased concentration of pre-existing antibodies which may act to mask a prevailing reduced responsiveness that appears to correlate with poor reactivity to vaccination $[27,28]$. With the advent of contemporary molecular profiling techniques a clearer picture of immune regulation is set to be established.

The factors that contribute to a decline of the immune system involve a reduction in the naive $\mathrm{T}$ cell population and a rise in the memory $\mathrm{T}$ cell population, particularly those displaying an effector memory phenotype. The naive $\mathrm{T}$ cell is a mature cell that has successfully undergone central selection within the thymus but has not yet encountered its cognate antigen in the periphery. Upon activation and proliferation triggered by a novel encounter with a pathogen, a naive T cell will produce an acquired immune response in which a reservoir of memory cells is retained for future exposure to the same pathogen [29]. The changes to the naive $\mathrm{T}$ cell population are connected to thymus involution whereby homeostatic proliferation occurs in order to sustain the population while naive T cell receptor (TCR) diversity is maintained until advanced age (Figure 1) [24,30,31]. This distortion of the naive T cell population that is caused by the immune system's endeavour to maintain homeostasis appears to contribute to age-related immune defects with notable changes occurring within the $\mathrm{CD}^{+} \mathrm{T}$ cell compartment. Hence, the study of CD8 ${ }^{+} \mathrm{T}$ cells aims to characterise these alterations in the aged immune system by assessing functional, phenotypic and proliferative responses across the human lifetime.

Functional Analysis to Assess Changes in the T Cell Population: Assessment of cytokine production by T cells is commonly utilised to determine their functional profile in response to antigenic stimulation. Cytokines are secreted in response to cellular activation and therefore are an important mediator of antiviral immunity [32]. Numerous cytokines are produced by CD $8^{+} \mathrm{T}$ cells in response to stimulation by antigen. Levels of interferon (IFN)- $\gamma$, tumour necrosis factor (TNF)- $\alpha$, interleukin (IL)- 2 and lysosomal-associated membrane protein 1 (also referred to as CD107a) have proven to be extremely reliable indicators of functional behaviour. Each may be measured at the level of protein expression, typically by enzyme-linked immunosorbent assay or flow cytometry, but increasingly commonly by more modern analytical approaches, such as gene expression profiling and mass cytometry. The extent of the $\mathrm{CD}^{+} \mathrm{T}$ cell response is a marker used to determine the reactivity of $\mathrm{T}$ cells and therefore the selection of multiple cytokines is used since the profile of a single cytokine may underestimate the full functional potential of the $\mathrm{T}$ cell population [33]. It has been suggested that polyfunctional T cells that produce simultaneously IFN- $\gamma$, TNF- $\alpha$, IL- 2 and CD107a are critical to control of infection [34-38].

The roles of IFN- $\gamma$ and TNF- $\alpha$ in clearance of microbial infection via induction of cellular antiviral proteins have been characterised in detail [39-43]. IFN- $\gamma$ is expressed by activated $\mathrm{CD}^{+} \mathrm{T}$ cells and binds to the IFN- $\gamma$ receptor that is expressed on all nucleated cells. Its antiviral properties include induction of macrophage activation. Furthermore, IFN- $\gamma$ induces surface molecule expression, influences the processing of endogenous antigens and is associated with apoptosis promotion or inhibition [39]. TNF- $\alpha$ is a proinflammatory cytokine that activates the signalling pathways for cell survival and differentiation, apoptosis, inflammatory responses and regulation of immune cells [32]. 


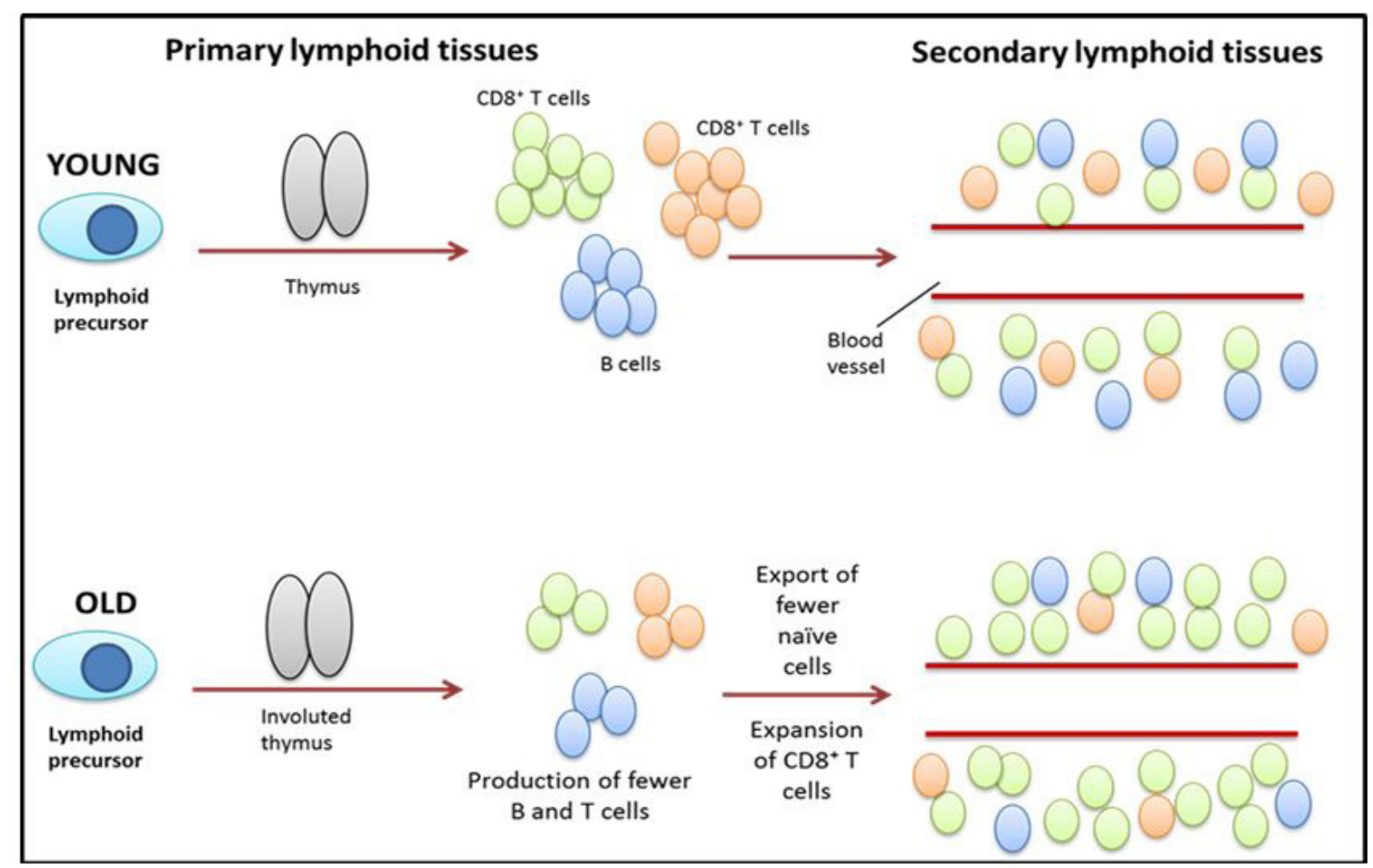

Figure 1: The effects of ageing on lymphocytes production and distribution. T cell population is decreased due to thymic involution causing fewer naive $\mathrm{T}$ cell to be exported. The distortion of the $\mathrm{T}$ cell repertoire and an increased number of terminally differentiated memory $\mathrm{CD} 8^{+} \mathrm{T}$ cell expansion. Modified from Dorshkind et al., 2009 [127].

IL-2 is secreted following autocrine activation of T cells via antigen binding and CD28+ co-stimulatory signals. IL-2 functions as a $\mathrm{T}$ cell chemoattractant that stimulates activated leucocytes to proliferate and promotes $\mathrm{CD} 8^{+} \mathrm{T}$ cell differentiation. IL-2 is also an important factor involved in self-tolerance and homeostasis [32]. CD107a is located in the cytotoxic granule membrane of activated $\mathrm{CD}^{+} \mathrm{T}$ cells, and which, upon cell activation and granule exocytosis, is expressed transiently, thus making this protein ideal as a marker of degranulation $[44,45]$.

Phenotypic Analysis to Characterise Changes in the T Cell Population: Assessment of T cell phenotypic markers have produced reliable information to define different antigen-specific $\mathrm{CD}^{+} \mathrm{T}$ cell populations and to identify $\mathrm{T}$ cell differentiation in humans [46]. However, owing to the inherent limitations of conducting clinical trials, much of what has been learned is owed to the experimental mouse model. Studies in mice have shown that functionally exhausted $\mathrm{T}$ cells display multiple co-stimulatory molecules [47]. In order to assess the phenotype of T cells, programmed cell death protein 1 (PD-1), T cell immunoglobulin mucin domain-3 (Tim-3), lymphocyte activation gene -3 (LAG-3) and CD244 are consistent determinants.

PD-1 and Tim-3 are linked with $\mathrm{CD}^{+} \mathrm{T}$ cell exhaustion throughout chronic viral infections, influencing their fate and/or differentiation. Upon antigen-specific activation, both are up-regulated on the surface of $\mathrm{CD}^{+} \mathrm{T}$ cells and transmit inhibitory signals that reduce proliferation, thereby controlling the accumulation of these T cells. Blockade of the PD-1 pathway in CMVinfected mice has been shown to restore the function of exhausted CD8 ${ }^{+} \mathrm{T}$ cells and therefore to reduce viral load. In addition, blocking of the Tim-3 pathway increases proliferation and cytokine secretion by $\mathrm{CD}^{+} \mathrm{T}$ cells significantly in response to antigen stimulation [48-52]. The inhibitory signalling molecule LAG-3 is involved directly in the negative regulation of T cell expansion and homeostasis [53-55]. CD8 ${ }^{+} \mathrm{T}$ cells express LAG-3 at low levels; however, further to antigenic stimulation, LAG-3 expression increases dramatically [55]. Lastly, CD244 is a member of the group of signalling lymphocyte activation molecules (SLAM) which are expressed on virus-specific CD8 ${ }^{+} \mathrm{T}$ cells. Cross-linking of CD244 can promote the duel function of occupation and activation of antigen-specific T cells, depending on the level of TCR expression [56].

Proliferative Analysis to Characterise Changes in the T Cell Population: Intracellular expression of Ki67 as a marker of in vivo cycling and the proportion of CD69 expression are often measured to investigate the antigen-specific proliferation of T cells following antigenic exposure. Ki67 is associated with cellular proliferation and is a marker used frequently for determining the growth fraction of a cell population due to its presence in all active phases of the cell cycle and mitosis [57-59]. CD69 is an early activation marker that is detectable within an hour of ligation of the TCR complex and is a T cell activation and proliferation costimulatory molecule [60]. CD69 is expressed only on activated T cells and not upon those in a resting state [61]. The comparison of cell populations after antigen stimulation on sequential days indicates the proliferative capacity of antigen-stimulated $\mathrm{T}$ cells. Suppression of $\mathrm{T}$ cell proliferation may also be measured in vitro by a variety of standard assays [62]. 


\section{$\mathrm{CD8}^{+} \mathrm{T}$ Cell Response to Viral Antigens}

The importance of the contribution of $\mathrm{CD}^{+} \mathrm{T}$ cells to the immune response to pathogens is well-recognised [63]. Antigen-specific $\mathrm{CD}^{+} \mathrm{T}$ cells emerge in the peripheral blood early after infection and respond to the viral-encoded peptides presented by major histocompatibility complex (MHC) class I molecules on the surface of infected cells or antigen-presenting cells (APC) [64]. A peptide/MHC class I complex is formed within an infected cell and transported to the cell membrane, which is targeted by CD8 ${ }^{+}$ TCR $[65,66]$. Naive T cells are activated in response to the viral antigens causing T cells to undergo expansion with the aim to control the viraemia. Recognition by $\mathrm{CD}^{+} \mathrm{T}$ cells of specific viral epitopes enables infected cells to be lysed via differing mechanisms [63]. Typically, after clearance of acute viral infection, there is significant contraction of the antigen-specific T cell population whereby a small percentage differentiate into memory $\mathrm{T}$ cells to enable recognition of virus-specific epitopes upon future exposure (Figure 2) [67]. However, persistent viral infections, of which CMV has been the most studied, drive the memory T cell pool into a further restricted repertoire in which the $\mathrm{T}$ cell population does not contract but remains to accumulate at a high frequency (Figure 3 ). This occurrence has been termed T cell memory inflation [68-70]. Memory inflation is observed in the elderly in whom repeated stimulation of $\mathrm{T}$ cells over a lifetime and maintenance of viral latency together contribute to the accumulation of memory $\mathrm{T}$ cells that comprises a significant component of the overall aged $\mathrm{T}$ cell repertoire [68]. As much as 50\% of the available $\mathrm{T}$ cell pool may show activation towards a single viral epitope, indicative of the vast commitment of the immune system to managing this one pathogen $[69,70]$. These antiviral $\mathrm{T}$ cells exhibit changes in the expression of genes associated with the cell cycle that may render virus-specific $\mathrm{T}$ cells less responsive to the proliferative signals required to induce cell division in response to exposure to antigen.

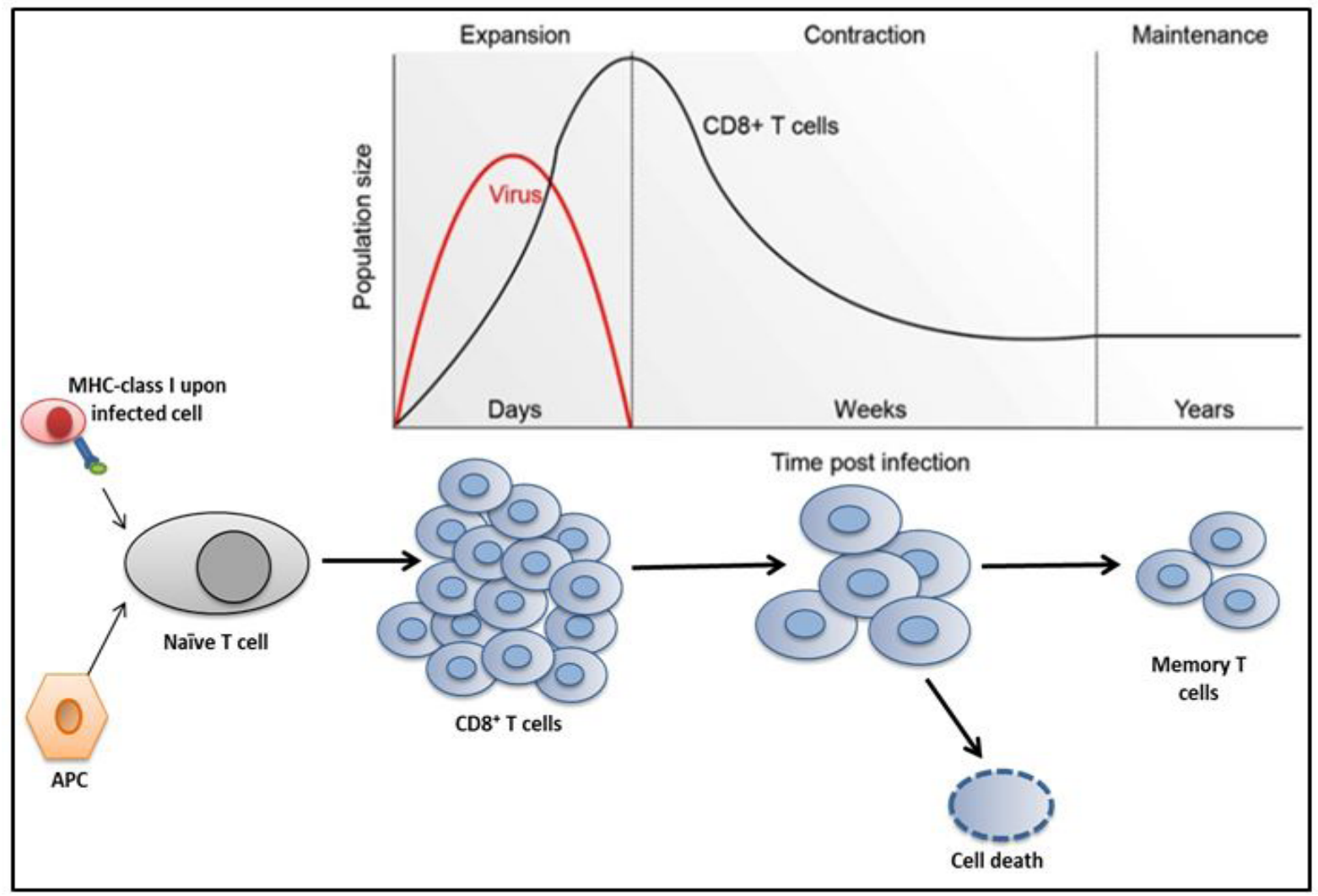

Figure 2: T cell activation and clonal expansion upon antigen stimulation. Modified from Russ et al., 2013 [128].

\section{Consequences of Immunosenescence}

The altered $\mathrm{T}$ cell compartment and the resulting functional consequences in the elderly appear to reflect in the reduced ability of the aged immune system to respond to vaccines and defend against pathogens. Several studies have documented that the immune response is low following influenza immunisation with an inactivated vaccine in the elderly (30-50\% protection) in comparison to the young (65-80\% protection) where poor response correlates with the expanded CD $8^{+} \mathrm{T}$ cell population [71-73]. It is therefore reasonable to speculate that the distortions in the $\mathrm{T}$ cell population reveal an immune system with functional impairment, particularly the $\mathrm{CD} 8^{+} \mathrm{T}$ cell compartment.

Age-Related Changes to $\mathrm{CD8}^{+} \mathbf{T}$ Cells: A diverse repertoire of T cells is maintained by continual replenishment in the thymus from where naive $\mathrm{T}$ cells are exported upon reaching maturity. The thymus involutes with age due to the changes in both the thymic microenvironment and $\mathrm{T}$ cell progenitor population but continues to remain active, albeit in a limited capacity, until advanced age [30]. However, the repertoire of naive T cells is compromised and in the absence of sufficient, pristine T cells exported from the thymus, existing $\mathrm{T}$ cells increasingly proliferate (sometimes changing phenotype to memory cells), which depletes further the naive T cell compartment $[30,74]$. In addition, exposure of the ageing host to antigens during their lifetime expands further the memory 
T cell pool. Lastly, among memory cells, a great many clonally expanded T cells form over time that eventually come to dominate the $\mathrm{T}$ cell memory pool, thereby restricting further cell diversity $[75,76]$. Such behaviour collectively contributes to the decline in diversity of the $\mathrm{CD}^{+} \mathrm{T}$ cell repertoire. Consequently, $\mathrm{CD}^{+} \mathrm{T}$ cell responses become inadequate upon encountering pathogens to which the person has not had prior exposure.

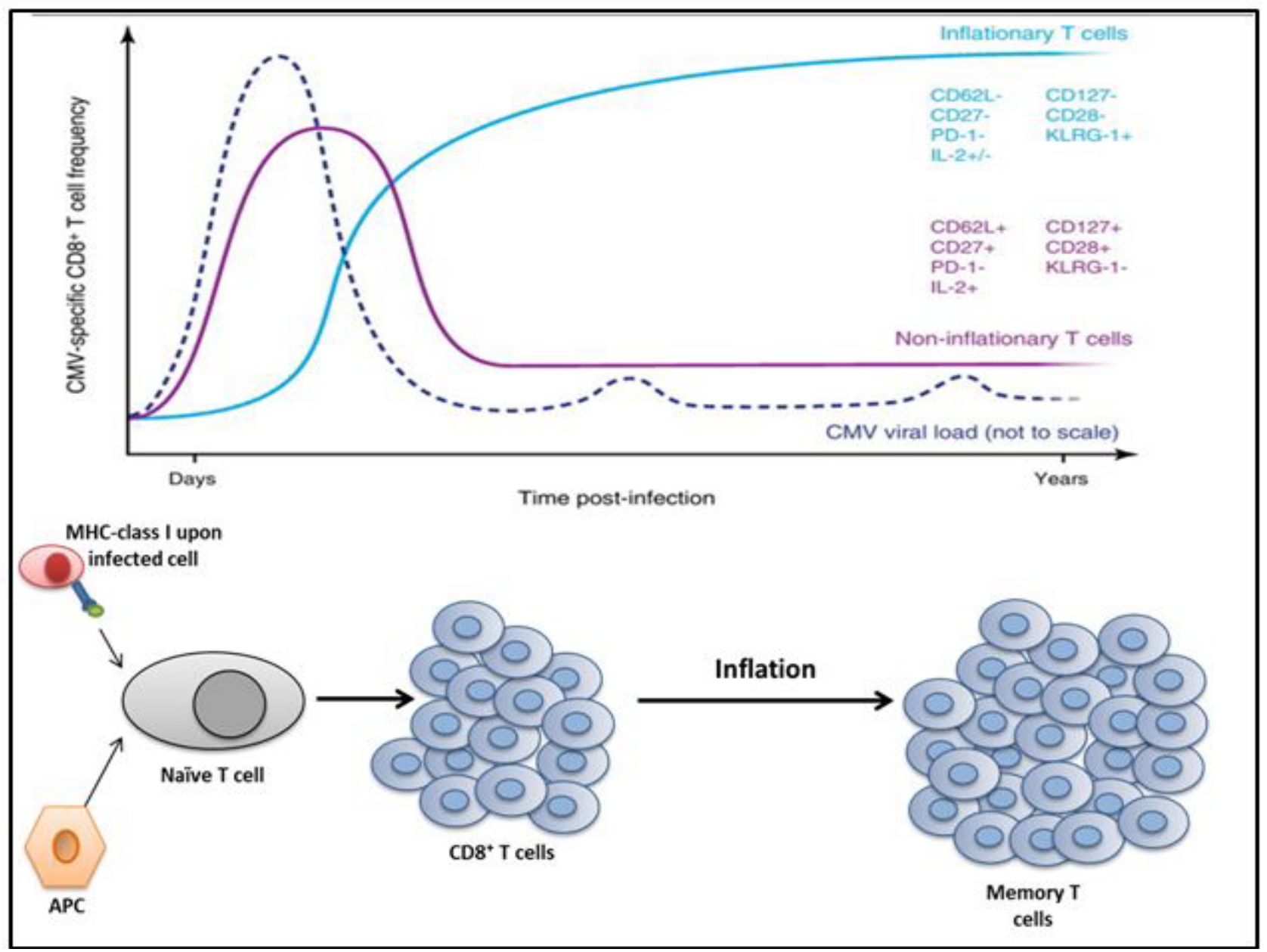

Figure 3: The development of CMV-specific T cells characterised by the lack of memory cell contraction and accumulation of cells over time. Modified from O'Hara et al., 2012 [129].

In summary, the changes that occur to the aged immune system are: (i) due to the host's immunological history differentiated and memory T cells accumulate in larger numbers; (ii) due to persistent antigen exposure the naive T cell population decreases; (iii) due to the physical limit of $\mathrm{T}$ cells in the body, there is an imbalance in the ratio of memory to naive T cells as daughter memory cells outnumber their parental naive cells.

\section{Role of Latent Infections in Driving Immunosenescence}

Immunosenescence presents as a multifactorial process that imposes a pressure on the body's homeostatic mechanisms to maintain a continuous pool of $\mathrm{T}$ cells for the majority of adulthood that is potentially responsible for their exhaustion and functional impairment. The consensus of opinion among researchers is shifting towards the view that persistent antigenic stress, and in particular exposure to chronic infections including CMV, plays a vital role in directing the exhaustion of $\mathrm{T}$ cells and induction of senescence $[3,4]$. CMV influences immunity by driving the accumulation of late-stage differentiated CD8 ${ }^{+} \mathrm{T}$ cells, i.e. by the process of memory inflation. As these cells remain latent in the host, they may be detected long after the virus has been controlled [69,70]. It has been proposed that the continued and lengthy stand-by status of the host's T cells demanded by persistent CMV infection exhausts the naive $\mathrm{T}$ cell reserve, hence leading to reduced clonal $\mathrm{T}$ cell diversity and impaired $\mathrm{T}$ cell functionality [77,78]. Thus, prolonged challenge with CMV may accelerate immunosenescence, as well as a person's biological ageing processes. Deficiencies in antigen processing and presenting, cytokine environment and maintenance of memory lymphocyte populations give rise to inadequate responses to newly evolving pathogens and a reduced efficacy in protection against infection via vaccination. These changes are poorly understood immunologically and from a clinical perspective have profound implications for the quality of life of elderly individuals [14]. 


\section{Cytomegalovirus (CMV)}

CMV is a ubiquitous beta human herpes virus that can infect a wide range of human tissues with subsequent secretion of the virus in bodily fluids in persons both young and old. CMV is highly species-specific and its evolutionary host adaptation is reflected in the notable number of host-tailored genes, which are usually non-essential for viral replication but that may play a role in virus-host interactions [79]. It is estimated that CMV infects 50-90\% of a given population, depending on socioeconomic status, geographical location and hygiene levels [80,81]. In Australia, the seroprevalence rate is approximately $72 \%$ over the age of 50 years; however, in certain ethnic groups, seroprevalence approaches $90 \%$ of an infected population [82,83]. Transmission occurs through direct contact with infectious bodily fluids, whereby sexual contact and interaction with children are common types of transmission [84,85]. CMV infection is acquired during childhood with disease prevalence generally increasing with age [85]. The changes in demographics will be significant if it is found that CMV is an important driving factor for immunosenescence.

\section{Infection}

During primary challenge to a host, CMV targets a broad range of cell types. This establishes an asymptomatic, latent, lifelong infection on which a large fraction of the immune system of the elderly is focused. Endothelial and epithelial cells are primary targets for infection, with particular predilection for the cells of the salivary glands and kidneys that are shed throughout body fluids during a person's lifetime [86]. The ensuing CMV infection generates two outcomes; infection of host fibroblasts leading to extensive viral replication and subsequent infection and/or latent infection resulting from CMV transcription programme suppression in undifferentiated myeloid cells [87]. The persistent nature of CMV infection is possibly related to latency and the ability of the virus to escape the host's immune surveillance by differing mechanisms through which the virus remains at a low level of lytic replication $[87,88]$. Recurrence occurs by reactivation of the endogenous virus within a seropositive individual [3,89]. Changes to the distribution of immune cells and to the selection of memory cells are rapid during primary infection, yet the precise sites where viral latency and reactivation are established have not been determined [90].

\section{Establishment of Viral Latency and Reactivation}

A common feature of CMV is to establish lifelong viral latency from which the viral genome is able to reactivate under favourable conditions. However, the extent to which latency is a mechanism for viral persistence is not known. Reactivation of CMV in adults is usually asymptomatic, making the virus difficult to identify and study. There is little evidence regarding the frequency of reactivation and the consequences of this on the ageing immune system. While the viral genome (genomic viral DNA) of $\mathrm{CMV}$ is detected within various cells types, the principal site of latency appears to reside in cells of the myeloid lineage [88]. The nature of the cellular environment that CMV encounters plays a critical role in determining the characteristics of infection and viral reactivation from latency [91]. Three possible pathways to enable establishment of CMV viral latency have been proposed. Following entry into an individual: (i) after viral attachment to a host cell, the virus enters latency, lacking de novo viral gene expression; (ii) productive infection is interrupted prematurely; and (iii) genes that are unrelated to replication but are necessary for successful latency are activated [63,91-94].

Evidence suggests that viral latency is a highly dynamic state, the mechanisms for which are remarkably varied. However, it is increasingly apparent that a significant event during latency is the suppression by cellular transcription factors of the major early promoter. This occurs in addition to post-transcriptional modifications of histone that promote and maintain a transcriptionally inactive state $[95,96]$. Recent studies have concluded that during latent infection expression of numerous viral gene products and production of cytokines, in particular TNF- $a$, may orchestrate substantial changes in latently infected cells and their surrounding environment, thereby facilitating the promotion of viral reactivation $[84,91,97]$.

\section{CMV-Specific CD8 ${ }^{+} \mathrm{T}$ Cell Response}

During infection, multiple components of the host immune system interact with CMV including NK cells, antibodies, CD4 $4^{+} \mathrm{T}$ cells and $\mathrm{CD}^{+} \mathrm{T}$ cells [98]. The most notable changes to the aged adaptive immune response to CMV take place in the CD8 ${ }^{+} \mathrm{T}$ cell compartment. Effector functions of CMV-specific $\mathrm{CD}^{+} \mathrm{T}$ cells include cytotoxicity and cytokine production, each of which has been shown to be important to control of infection. Cytotoxicity follows activation and causes apoptosis of the target cell. This occurs via both granule-dependent and-independent pathways. The former mechanism utilises lytic granules located within the cell cytoplasm and upon CD8 ${ }^{+}$TCR activation, lysosomal-associated membrane proteins (LAMP) including CD107a and CD107b are exposed. Cytokines are secreted after CD8 ${ }^{+} \mathrm{T}$ cell activation, which include IL-2, IFN- $\gamma$ and TNF- $\alpha$. Quantification of CMVspecific CD8 ${ }^{+} \mathrm{T}$ cell function has clinical relevance and is therefore integral to monitoring CMV activity [46,68,99-102].

Cell Inflation and Exhaustion: The T cell response to CMV involves a large pool of $\mathrm{CD} 8^{+} \mathrm{T}$ cells that remains in circulation during latency. These apparently resting $\mathrm{CD}^{+} \mathrm{T}$ cells contain cytotoxic granules and potentially produce IFN- $\gamma$ while awaiting viral reactivation [102]. The majority of CMV-specific $\mathrm{CD}^{+} \mathrm{T}$ cells have a terminally differentiated effector memory (TEMRA) T cell phenotype displaying reduced CD28, CD27, CCR7 and CD62, increased CD57 and re-expression of the surface marker CD45RA $[103,104]$. An initial study to define changes in the $\mathrm{CD}^{+} \mathrm{T}$ cell compartment showed that CD4 ${ }^{+} \mathrm{CD} 28^{-}$and $\mathrm{CD} 8^{+} \mathrm{CD} 27^{-} \mathrm{T}$ cell levels increased two-to-three fold in CMV-infected older individuals and that the changes were specific to CMV [105]. This finding was confirmed by several reports showing an expansion of the $\mathrm{CD} 4^{+} \mathrm{CD} 28^{-}$compartment, but in particular a massive rise in the CD27-CD8 ${ }^{+} \mathrm{T}$ cell population in CMV-positive older individuals with fewer naive T cells [106-109]. Comparable results were at- 
Journal of Immunology and Infectious Diseases

ained by studying a cohort of CMV-positive elderly individuals (60+ years of age) who displayed approximately $20 \%$ more T cells in comparison to CMV-negative individuals [110]. In addition, the elderly displayed a $41 \%$ increase in CD $8^{+} \mathrm{T}$ cells associated with an increased memory pool in comparison to the younger cohort. A heightened TEMRA profile following CMV infection may contribute to the so-called 'inflamm-aging' phenomenon, upregulation of the inflammatory response that occurs with advancing age [111,112]. Although the naive T cell pool diminishes naturally with age, it is particularly low in CMV-positive individuals [110]. The resulting net increase of $\mathrm{CD}^{+} \mathrm{T}$ cells reduces the CD4:CD8 ratio, a hallmark of immunosenescence. CMV has additionally proven to drive oligoclonal expansion in the aged individual. Studies of the TCR of CMV-specific CD $8^{+} \mathrm{T}$ cells indicated that clonal populations increase with age. Expansion results in approximately $25 \%$ of the $\mathrm{T}$ cell compartment and increases in the CMVpositive elderly $[111,112]$. Along with the size of response, the TEMRA T cell phenotype makes the CMV-specific T cell population unique [103].

The ageing process and a reduction in T cell diversity are associated and CMV infection drives the T cell population further towards a restricted repertoire. Although it appears that senescence is displayed at the level of the individual cell, the total number of cells is massive and therefore overall reactivity is enhanced and not reduced [113]. This indicates that the traits of immunosenescence are significant contributors to CMV infection and supports the concept that CMV is a causal factor in the age-associated accumulation of late-differentiated $\mathrm{CD}^{+} \mathrm{T}$ cells, which places the elderly into an at-risk group [113]. It has been suggested that these cells are dysfunctional since a smaller proportion of T cells from aged donors respond to antigenic stimulation in vitro than that from young donors. However, as mentioned, the response of the cell population in the elderly is enhanced because of T cell inflation. This raises the question as to whether the 'senescent' cells that remain in circulation are deleterious or necessary to control infection, and, if these changes are not triggered specifically by CMV, are they associated exclusively with the ageing process? It has been postulated that as a consequence of the combined effects of a massive $\mathrm{T}$ cell expansion, loss of circulating naive $\mathrm{T}$ cells and thymus involution as seen during CMV infection in the elderly, the $\mathrm{CD}^{+} \mathrm{T}$ cell pool becomes exhausted, causing a functional loss of memory cells $[102,104]$. During persistent viral infections, there are substantial alterations to $\mathrm{CD}^{+} \mathrm{T}$ cell phenotype and functionality due to the possibility of a failure of virus-specific $\mathrm{T}$ cells to differentiate into fully functional memory $\mathrm{T}$ cells. This is indicative of a progressive loss of $\mathrm{CD}^{+} \mathrm{T}$ cell function (termed 'exhaustion') [114]. In turn, this implies that the exhaustion of both naive T cells and agedependent, replicative memory CD8 ${ }^{+} \mathrm{T}$ cells is accelerated by CMV infection, especially in the absence of an adequate renewal of naive $\mathrm{T}$ cells from the thymus as a consequence of involution [115]. The process generates the characteristic phenotype of CMVspecific T cells, in particular the loss of the CD28 surface marker. CD28 interacts with CD80 and/or CD86 (which are presented on activated APC), providing stimulus for T cell activation and differentiation. CD28 receptor signalling overcomes the pathway for auto-inhibition of sustained T cell activation and production of IL-2. In addition, a decrease in telomerase activity due to the loss of CD28-mediated Akt signalling (involved in cell proliferation and transcription) contributes further to the exhaustion of T cells [116].

Shortened Telomere Length: Telomeres form a complex protein-DNA structure at the ends of chromosomes that protects them from degradation. Changes in the structure and function of telomeres are thought to play a role in malignant transformation and cellular senescence [117]. Recent studies have investigated the length of telomeres of CMV-specific CD8 ${ }^{+} \mathrm{T}$ cells [118-120]. Infection with CMV results in a large pool of $\mathrm{CD} 8^{+} \mathrm{T}$ cells that are terminally differentiated. As a consequence, the lymphocyte pool produces a $\mathrm{CD}^{+} \mathrm{T}$ cells subset with shortened telomere lengths that is maintained for three years post-infection [121]. Although a shortening of telomere length correlates with age, it is apparent that CMV infection exacerbates this effect. In one study, individuals who are CMV-positive displayed a loss of 94 base pairs per year in comparison to CMV-negative individuals who showed a loss of 74 base pairs per year; this difference correlated with the degree of CD8 ${ }^{+} \mathrm{T}$ cell differentiation [120]. This finding supports the notion that infection with CMV accelerates, or at least assists, the development of immunosenescence.

\section{CMV, Immunosenescence and Immune Risk Profile}

It is becoming evident that the interaction of CMV with the aged immune system drives production of dysfunctional T cells, leading to the development of immunosenescence. In the elderly, the response of $\mathrm{CD} 8^{+} \mathrm{T}$ cells can be pronounced and is possibly responsible for the characteristic $\mathrm{T}$ cell profile of the aged immune system. However, the relationship between changes in the $\mathrm{T}$ cell compartment and the definition of functional immunosenescence remains unclear. The link was first investigated by Swedish longitudinal and subsequent OCTO/NONA-immune studies, from which the mortality predictive biomarker of immune health termed the 'immune risk profile' (IRP) was established [122,123]. This study ascertained that IRP was associated strongly with CMV seropositivity in addition to inflated $\mathrm{CD}^{+} \mathrm{T}$ cell populations. These were noted to cause an inversion of the CD4:CD8 T cell ratio, constituting a profile aligned to increased mortality at 2, 4 and 6 years' follow-up of people 85 years old at baseline [90]. This immune profile has since been shown to exist in hexagenerians, but significantly more so in men than in women [124]. The role of immunity in survival and the impact of lifetime exposure to pathogens raise the issue of whether immunological age is a better biomarker than chronological age. Hence, the influence of CMV in driving immunosenescence is a focus of continuing research.

\section{Future Research Directions}

The ageing process has a profound effect on human physiology and is associated with the decline of some of the biological functions of the body $[73,125]$. Thus, it is important to distinguish between the consequences of a healthy ageing process and ageing due to interactions with pathogens. While it is recognised that dysregulation of the immune system that results in increased susceptibility 
to disease is linked with ageing, the causes have not been determined. As discussed, CMV appears to be a driver behind the observed phenomenon of CD8 ${ }^{+} \mathrm{T}$ cell differentiation with ageing. The intensity of the immune response by the immune system to $\mathrm{CMV}$, which appears to increase with age, represents an enormous commitment of resources to controlling a single virus, suggesting that CMV modulates the immune ageing process and therefore could have an impact on survival. The questions arise as to whether CMV is a causative factor for immunosenescence and to what extent infection influences longevity. In order to assess the immune response to $\mathrm{CMV}$, examining the differences in $\mathrm{T}$ cell responses, polyfunctionality and phenotypical characterisation of antigen-specific $\mathrm{CD}^{+} \mathrm{T}$ cells will aid dissecting the effects of impaired immune capacity in the elderly.

\section{Conclusion}

Why and how $\mathrm{CD}^{+} \mathrm{T}$ cells memory inflation occurs in some people but not others, and if this inflation is associated with defects in $\mathrm{T}$ cell programming that renders them less efficient in controlling CMV, remains poorly defined. To date, there is no effective CMV vaccine available and although antiviral therapy is prescribed, drug delivery is difficult and the drugs themselves have a dose-dependent toxicity. In addition, drug-resistant CMV can occur $[85,126]$. Future investigations should focus on the functional and proliferative properties of human CMV-specific T cells that may provide detailed information regarding the complexities of interaction between the aged immune system and CMV infection.

Understanding the pathogenic alterations of immune functions may help to explain different characteristics of the ageing process, including development of age-associated disorders. This indicates that the immune response to a single pathogen may compromise $\mathrm{CD}^{+} \mathrm{T}$ cell diversity and the capacity of the host cell to counter challenge by further pathogens. It may be hypothesized that memory $\mathrm{T}$ cell inflation of CMV-infected individuals and ageing together influence the functional and proliferative properties of human CMV-specific T cells, thereby rendering them less efficient at controlling virus reactivation.

\section{Acknowledgement}

The authors' research is supported by Central Queensland University and the Australian Government's Collaborative Research Networks Program. Sarah Young (CQU), Corey Smith and Rajiv Khanna (QIMR Berghofer Medical Research Institute, Brisbane, Australia) are thanked for valuable comments during preparation of this manuscript.

The authors declare no competing interests.

\section{References}

1. WHO (2015) Ageing and life-course, Switzerland.

2. Virgin HW, Wherry EJ, Ahmed R (2009) Redefining chronic viral infection. Cell 138: 30-50.

3. Moss P (2010) The emerging role of cytomegalovirus in driving immune senescence: a novel therapeutic opportunity for improving health in the elderly. Curr Opin Immunol 22: 529-34.

4. Pawelec G, Derhovanessian E (2011) Role of CMV in immune senescence. Virus Res 157: 175-9.

5. Pawelec G (2012) Hallmarks of human "immunosenescence": adaptation or dysregulation? Immun Ageing 9: 15.

6. Pawelec G, Akbar A, Beverley P, Caruso C, Derhovanessian E, et al. (2010) Immunosenescence and Cytomegalovirus: where do we stand after a decade? Immun Ageing 7: 13.

7. Solana R, Tarazona R, Aiello AE, Akbar AN, Appay V, et al. (2012) CMV and Immunosenescence: from basics to clinics. Immun Ageing 9: 23.

8. Solana R, Tarazona R, Gayoso I, Lesur O, Dupuis G, et al. (2012) Innate immunosenescence: effect of aging on cells and receptors of the innate immune system in humans. Semin Immunol 24: 331-41.

9. Murciano C, Villamón E, Yáñez A, O’Connor JE, Gozalbo D, et al. (2006) Impaired immune response to Candida albicans in aged mice. J Med Microbiol 55: 1649-56.

10. Duraisingham SS, Rouphael N, Cavanagh MM, Nakaya HI, Goronzy JJ, et al. (2013) Systems biology of vaccination in the elderly In: Systems Biology, Springer, Germany.

11. Poland GA, Ovsyannikova IG, Kennedy RB, Lambert ND, Kirkland JL (2014) A systems biology approach to the effect of aging, immunosenescence and vaccine response. Curr Opin Immunol 29: 62-8.

12. Australian Institute of Health and Welfare (2006) Mortality over the twentieth century in Australia: trends and patterns in major causes of death, Australia.

13. Aberle JH, Puchhammer-Stöckl E (2012) Age-dependent increase of memory B cell response to cytomegalovirus in healthy adults. Exp Gerontol 47: 654-7.

14. Sansoni P, Vescovini R, Fagnoni FF, Akbar A, Arens R, et al. (2014) New advances in CMV and immunosenescence. Exp Gerontol 55: 54-62.

15. Gomez CR, Nomellini V, Faunce DE, Kovacs EJ (2008) Innate immunity and aging. Exp Gerontol 43: 718-28.

16. Shaw AC, Goldstein DR, Montgomery RR (2013) Age-dependent dysregulation of innate immunity. Nat Rev Immunol 13: 875-87.

17. Sun JC, Lanier LL (2009) The natural selection of herpesviruses and virus-specific NK cell receptor. Viruses 1: $362-82$.

18. Vermijlen D, Brouwer M, Donner C, Liesnard C, Tackoen M, et al. (2010) Human cytomegalovirus elicits fetal $\gamma \delta$ T cell responses in utero. J Exp Med 207: 807-21.

19. Wistuba-Hamprecht K, Frasca D, Blomberg B, Pawelec G, Derhovanessian E (2013) Age associated alterations in $\gamma \delta$ T-cells are present predominantly in individuals infected with Cytomegalovirus. Immun Ageing 10: 26.

20. Müller L, Fülöp T, Pawelec G (2013) Immunosenescence in vertebrates and invertebrates. Immun Ageing 10: 12.

21. Rote NS (2012) Adaptive Immunity In: Understanding Pathophysiology ( $5^{\text {th }}$ edn) Elsevier - Health Sciences Division Publisher, USA. 
22. Wertheimer AM, Bennett MS, Park B, Uhrlaub JL, Martinez C, et al. (2014) Aging and cytomegalovirus infection differentially and jointly affect distinct circulating T cell subsets in humans. J Immunol 192: 2143-55.

23. McElhaney JE, Effros RB (2009) Immunosenescence: what does it mean to health outcomes in older adults? Curr Opin Immunol 21: 418-24.

24. Linton PJ, Dorshkind K (2004) Age-related changes in lymphocyte development and function. Nat Immunol 5: 133-9.

25. Min H, Montecino-Rodriguez E, Dorshkind K (2005) Effects of aging on early B- and T-cell development. Immunol Rev 205: 7-17.

26. Nikolich-Žugich J, Rudd BD (2010) Immune memory and aging: an infinite or finite resource? Curr Opin Immunol 22: 535-40.

27. Chen WH, Kozlovsky BF, Effros RB, Grubeck-Loebenstein B, Edelman R, et al. (2009) Vaccination in the elderly: an immunological perspective. Trends Immunol 30: 351-9.

28. Ongrádi J, Stercz B, Kövesdi V, Vértes L (2009) Immunosenescence and vaccination of the elderly, I. Age-related immune impairment. Acta Microbiol Immunol Hung 56: 199-210.

29. Berard M, Tough DF (2002) Qualitative differences between naive and memory T cells. Immunology 106: 127-38.

30. Jamieson BD, Douek DC, Killian S, Hultin LE, Scripture-Adams DD, et al. (1999) Generation of functional thymocytes in the human adult. Immunity 10: 569-75.

31. Cavalieri S, Cazzaniga S, Geuna M, Magnani Z, Bordignon C, et al. (2003) Human T lymphocytes transduced by lentiviral vectors in the absence of TCR activation maintain an intact immune competence. Blood 102: 497-505.

32. Abbas AK, Lichtman AH, Pillai S (2010) Cytokines. In: Cellular and Molecular Immunology ( $6^{\text {th }}$ edn), Saunders Elsevier, Philadelphia, USA $267-301$.

33. Seder RA, Darrah PA, Roederer M (2008) T-cell quality in memory and protection: implications for vaccine design. Nat Rev Immunol 8: 247-58.

34. Bunde T, Kirchner A, Hoffmeister B, Habedank D, Hetzer R, et al. (2005) Protection from cytomegalovirus after transplantation is correlated with immediate early 1-specific CD8 T cells. J Exp Med 201: 1031-6.

35. Casazza JP, Betts MR, Price DA, Precopio ML, Ruff LE, et al. (2006) Acquisition of direct antiviral effector functions by CMV-specific CD4 ${ }^{+}$T lymphocytes with cellular maturation. J Exp Med 203: 2865-77.

36. Schwanninger A, Weinberger B, Weiskopf D, Herndler-Brandstetter D, Reitinger S, et al. (2008) Age-related appearance of a CMV-specific high-avidity CD8 ${ }^{+}$ $\mathrm{T}$ cell clonotype which does not occur in young adults. Immun Ageing 5: 14.

37. Sund F, Lidehäll AK, Claesson K, Foss A, Tötterman TH, et al. (2010) CMV-specific T-cell immunity, viral load, and clinical outcome in seropositive renal transplant recipients: a pilot study. Clin Transplant 24: 401-9.

38. Zelini P, Lilleri D, Comolli G, Rognoni V, Chiesa A, et al. (2010) Human cytomegalovirus-specific CD4 ${ }^{+}$and CD8 ${ }^{+}$T-cell response determination: comparison of short-term $(24 \mathrm{~h})$ assays vs long-term (7-day) infected dendritic cell assay in the immunocompetent and the immunocompromised host. Clin Immunol 136: 269-81.

39. Shtrichman R, Samuel CE (2001) The role of gamma interferon in antimicrobial immunity. Curr Opin Microbiol 4: 251-9.

40. opp E, Medzhitov R (2003) Recognition of microbial infection by Toll-like receptors. Curr Opin Immunol 15: 396-401.

41. Billiau A, Matthys P (2009) Interferon- $\gamma$ : a historical perspective. Cytokine Growth Factor Rev 20: 97-113.

42. Turner MD, Nedjai B, Hurst T, Pennington DJ (2014) Cytokines and chemokines: At the crossroads of cell signalling and inflammatory disease. Biochim Biophys Acta 1843: 2563-82.

43. Bieber K, Autenrieth SE (2015) Insights how monocytes and dendritic cells contribute and regulate immune defense against microbial pathogens. Immunobiology 220: $215-26$.

44. Aktas E, Kucuksezer UC, Bilgic S, Erten G, Deniz G (2009) Relationship between CD107a expression and cytotoxic activity. Cell Immunol $254: 149-54$.

45. Chan KS, Kaur A (2007) Flow cytometric detection of degranulation reveals phenotypic heterogeneity of degranulating CMV-specific CD8 ${ }^{+} \mathrm{T}$ lymphocytes in rhesus macaques. J Immunol Methods 325: 20-34.

46. Harari A, Dutoit V, Cellerai C, Bart P-A, Du Pasquier RA, et al. (2006) Functional signatures of protective antiviral T-cell immunity in human virus infections. Immunol Rev 211: 236-54.

47. Wherry EJ, Ha S-J, Kaech SM, Haining WN, Sarkar S, et al. (2007) Molecular signature of CD8 ${ }^{+} \mathrm{T}$ cell exhaustion during chronic viral infection. Immunity 27: $670-84$.

48. Francisco LM, Sage PT, Sharpe AH (2010) The PD-1 pathway in tolerance and autoimmunity. Immunol Rev 236: 219-42.

49. Peretz Y, He Z, Shi Y, Yassine-Diab B, Goulet JP, et al. (2012) CD160 and PD-1 co-expression on HIV-specific CD8 T cells defines a subset with advanced dysfunction. PLoS Pathog 8: e1002840.

50. Wu W, Shi Y, Li S, Zhang Y, Liu Y, et al. (2012) Blockade of Tim-3 signaling restores the virus-specific CD8 ${ }^{+}$T-cell response in patients with chronic hepatitis B. Eur J Immunol 42: 1180-91.

51. Han G, Chen G, Shen B, Li Y (2013) Tim-3: an activation marker and activation limiter of innate immune cells. Front Immunol 4: 449.

52. Hong JJ, Amancha PK, Rogers K, Ansari AA, Villinger F (2013) Re-evaluation of PD-1 expression by T cells as a marker for immune exhaustion during SIV infection. PLoS ONE 8: e60186.

53. Workman CJ, Dugger KJ, Vignali DA (2002) Cutting edge: molecular analysis of the negative regulatory function of lymphocyte activation gene-3. J Immunol 169: 5392-5.

54. Workman CJ, Vignali DA (2003) The CD4-related molecule, LAG-3 (CD223), regulates the expansion of activated T cells. Eur J Immunol 33: 970-9.

55. Workman CJ, Vignali DAA (2005) Negative regulation of T cell homeostasis by lymphocyte activation gene-3 (CD223). J Immunol 174: 688-95.

56. Chlewicki LK, Velikovsky CA, Balakrishnan V, Mariuzza RA, Kumar V (2008) Molecular basis of the dual functions of 2B4 (CD244). J Immunol 180: 8159-67.

57. Scholzen T, Gerdes J (2000) The Ki-67 protein: from the known and the unknown. J Cell Physiol 182: 311-22.

58. Brown DC, Gatter KC (2002) Ki67 protein: the immaculate deception? Histopathology 40: 2-11.

59. Shedlock DJ, Talbott KT, Morrow MP, Ferraro B, Hokey DA, et al. (2010) Ki-67 staining for determination of rhesus macaque T cell proliferative responses ex vivo. Cytometry A 77: 275-84. 
60. Peterson CC, Nederby L, Roug AS, Skovbo A, Peterslund NA, et al. (2011) Increased expression of CD69 on T cells as an early immune marker for human cytomegalovirus reactivation in chronic lymphocytic leukemia patients. Viral Immunol 24: 165-9.

61. Sancho D, Gómez M, Sanchez-Madrid F (2005) CD69 is an immunoregulatory molecule induced following activation. Trends Immunol 26: 136-40.

62. Collison LW, Vignali DAA (2011) In vitro Treg suppression assays. Methods Mol Biol 707: 21-37.

63. Crough T, Khanna R (2009) Immunobiology of human cytomegalovirus: from bench to bedside. Clin Microbiol Rev 22: 76-98.

64. Haring JS, Badovinac VP, Harty JT (2006) Inflaming the CD8 ${ }^{+} \mathrm{T}$ cell response. Immunity 25: 19-29.

65. Flutter B, Gao B (2004) MHC class I antigen presentation - recently trimmed and well presented. Cell Mol Immunol 1: 22-30.

66. Purcell AW, Elliott T (2008) Molecular machinations of the MHC-I peptide loading complex. Curr Opin Immunol 20: 75-81.

67. Smith-Garvin JE, Koretzky GA, Jordan MS (2009) T cell activation. Annu Rev Immunol 27: 591-619.

68. Karrer U, Sierro S, Wagner M, Oxenius A, Hengel H, et al. (2003) Memory inflation: continuous accumulation of antiviral CD8+ T cells over time. J Immunol 170: 2022-9.

69. Le Saux S, Weyand CM, Goronzy JJ (2012) Mechanisms of immunosenescence: lessons from models of accelerated immune aging. Ann NY AcadSci 1247: 69-82.

70. Sims S, Klenerman P (2014) Increasing inflationary T-cell responses following transient depletion of MCMV-specific memory T cells. Eur J Immunol 45: 113-8. 71. Effros RB (2007) Role of T lymphocyte replicative senescence in vaccine efficacy. Vaccine 25: 599-604.

72. Buchholz VR, Neuenhahn M, Busch DH (2011) CD8 ${ }^{+} \mathrm{T}$ cell differentiation in the aging immune system: until the last clone standing. Curr Opin Immunol 23: 549-54.

73. Muller L, Pawelec G (2014) Aging and immunity - impact of behavioural intervention. Brain Behav Immun 39: 8-22.

74. Haluszczak C, Akue AD, Hamilton SE, Johnson LD, Pujanauski L, et al. (2009) The antigen-specific CD8 ${ }^{+}$T cell repertoire in unimmunized mice includes memory phenotype cells bearing markers of homeostatic expansion. J Exp Med 206: 435-48.

75. Wherry EJ, Ahmed R (2004) Memory CD8 T-cell differentiation during viral infection. J Virol 78: 5535-45.

76. Messaoudi I, Warner J, Nikolich-Zugich D, Fischer M, Nikolich-Zugich J (2006) Molecular, cellular, and antigen requirements for development of age-associated T cell clonal expansions in vivo. J Immunol 176: 301-8.

77. Pawelec G (2014) Immunosenenescence: role of cytomegalovirus. Exp Gerontol 54: 1-5.

78. Lemmermann NA, Bohm V, Holtappels R, Reddehase MJ (2011) In vivo impact of cytomegalovirus evasion of CD8 T-cell immunity: facts and thoughts based on murine models. Virus Res 157: 161-74.

79. Cannon MJ, Schmid DS, Hyde TB (2010) Review of cytomegalovirus seroprevalence and demographic characteristics associated with infection. Rev Med Virol 20: 202-13.

80. Joseph A, Mahida N, Irving W, Soo S (2014) Congenital cytomegalovirus infection. Paediatr Child Health 24: 255-9.

81. Seale H, MacIntyre CR, Gidding HF, Backhouse JL, Dwyer DE, et al. (2006) National serosurvey of cytomegalovirus in Australia. Clin Vaccine Immunol 13: 1181-4.

82. Han XY (2007) Epidemiologic analysis of reactivated cytomegalovirus antigenemia in patients with cancer. J Clin Microbiol 45: $1126-32$.

83. Reeves M, Sinclair J (2008) Aspects of human cytomegalovirus latency and reactivation. Curr Top Microbiol Immunol 325: 297-313.

84. Krause PR, Bialek SR, Boppana SB, Griffiths PD, Laughlin CA, et al. (2013) Priorities for CMV vaccine development. Vaccine 32: 4-10.

85. Revello MG, Gerna G (2010) Human cytomegalovirus tropism for endothelial/epithelial cells: scientific background and clinical implications. Rev Med Virol 20: 136-55.

86. Sinclair J (2010) Chromatin structure regulates human cytomegalovirus gene expression during latency, reactivation and lytic infection. Biochim Biophys Acta 1799: $286-95$.

87. Sinclair J (2008) Human cytomegalovirus: latency and reactivation in the myeloid lineage. J ClinVirol 41: 180-5.

88. Krmpotic A, Bubic I, Polic B, Lucin P, Jonjic S (2003) Pathogenesis of murine cytomegalovirus infection. Microbes Infect 5: $1263-77$.

89. Derhovanessian E, Larbi A, Pawelec G (2009) Biomarkers of human immunosenescence: impact of Cytomegalovirus infection. Curr Opin Immunol 21: 440-5.

90. Sinclair JH, Reeves MB (2013) Human cytomegalovirus manipulation of latently infected cells. Viruses 5: 2803-24.

91. Goodrum FD, Jordan CT, High K, Shenk T (2002) Human cytomegalovirus gene expression during infection of primary hematopoietic progenitor cells: a model for latency. Proc Natl Acad Sci USA 99: 16255-60.

92. Reeves MB, Lehner PJ, Sissons JGP, Sinclair JH (2005) An in vitro model for the regulation of human cytomegalovirus latency and reactivation in dendritic cells by chromatin remodelling. J Gen Virol 86: 2949-54.

93. Cheung AKL, Abendroth A, Cunningham AL, Slobedman B (2006) Viral gene expression during the establishment of human cytomegalovirus latent infection in myeloid progenitor cells. Blood 108: 3691-9.

94. Reeves MB (2011) Chromatin-mediated regulation of cytomegalovirus gene expression. Virus Res 157: 134-43.

95. Reeves M, Sinclair J (2013) Regulation of human cytomegalovirus transcription in latency: beyond the major immediate-early promoter. Viruses 5: 1395-413.

96. Rubin RH (2007) The pathogenesis and clinical management of cytomegalovirus infection in the organ transplant recipient: the end of the 'silo hypothesis'. Curr Opin Infect Dis 20: 399-407.

97. Pantaleo G, Harari A (2006) Functional signatures in antiviral T-cell immunity for monitoring virus-associated diseases. Nat Rev Immunol 6: 417-23.

98. Ebert S, Podlech J, Gillert-Marien D, Gergely KM, Büttner JK, et al. (2012) Parameters determining the efficacy of adoptive CD8 T-cell therapy of cytomegalovirus infection. Med Microbiol Immunol 201: 527-39.

99. Jackson SE, Mason GM, Wills MR (2011) Human cytomegalovirus immunity and immune evasion. Virus Res 157: 151-60.

100. Motta VN, Martins SL. (2008) Impairment of cytomegalovirus-specific cellular immune response as a risk factor for cytomegalovirus disease in transplant recipients. Braz J Med Biol Res 41: 5-11. 
101. ten Berge IJ, van Lier RA. (2014) The interaction between cytomegalovirus and the human immune system. Immunol Lett 162: 141-4.

102. Appay V, Dunbar PR, Callan M, Klenerman P, Gillespie GM, et al. (2002) Memory CD8 ${ }^{+}$T cells vary in differentiation phenotype in different persistent virus infections. Nat Med 8: 379-85.

103. Fülöp T, Larbi A, Pawelec G (2013) Human T cell aging and the impact of persistent viral infections. Front Immunol 4: 271.

104. Looney RJ, Falsey A, Campbell D, Torres A, Kolassa J, et al. (1999) Role of cytomegalovirus in the T cell changes seen in elderly individuals. Clin Immunol 90: 213-9.

105. Snyder CM, Loewendorf A, Bonnett EL, Croft M, Benedict CA, et al. (2009) CD4 ${ }^{+}$T cell help has an epitope-dependent impact on CD8 ${ }^{+}$T cell memory inflation during murine cytomegalovirus infection. J Immunol 183: 3932-41.

106. Snyder CM, Cho KS, Bonnett EL, Allan JE, Hill AB (2011) Sustained CD8 ${ }^{+}$T cell memory inflation after infection with a single-cycle cytomegalovirus. PLoS Pathog 7: e1002295.

107. Walton SM, Torti N, Mandaric S, Oxenius A (2011) T-cell help permits memory CD8 ${ }^{+}$T-cell inflation during cytomegalovirus latency. Eur J Immunol 41: 2248-59.

108. Torti N, Oxenius A (2012) T cell memory in the context of persistent herpes viral infections. Viruses 4: 1116-43.

109. Chidrawar S, Khan N, Wei W, McLarnon A, Smith N, et al. (2009) Cytomegalovirus-seropositivity has a profound influence on the magnitude of major lymphoid subsets within healthy individuals. Clin Exp Immunol 155: 423-32.

110. Baylis D, Bartlett DB, Patel HP, Roberts HC (2013) Understanding how we age: insights into inflammaging. Longev Healthspan 2: 8.

111. Franceschi C, Campisi J (2014) Chronic inflammation (inflammaging) and its potential contribution to age-associated diseases. J Gerontol A Biol Sci Med Sci 69 Suppl 1: S4-9.

112. Khan N, Shariff N, Cobbold M, Bruton R, Ainsworth JA, et al. (2002) Cytomegalovirus seropositivity drives the CD8 T cell repertoire toward greater clonality in healthy elderly individuals. J Immunol 169: 1984-92.

113. Hadrup SR, Strindhall J, Køllgaard T, Seremet T, Johansson B, et al. (2006) Longitudinal studies of clonally expanded CD8 T cells reveal a repertoire shrinkage predicting mortality and an increased number of dysfunctional cytomegalovirus-specific T cells in the very elderly. J Immunol 176: $2645-53$.

114. Almanzar G, Schwaiger S, Jenewein B, Keller M, Würzner R, et al. (2004) IFN- $\gamma$ production by CMV-specific CD8 ${ }^{+}$T cells is high in elderly donors. Exp Gerontol 39: 863-5.

115. Wherry EJ (2011) T cell exhaustion. Nat Immunol 12: 492-9.

116. Bjørgo E, Taskén K (2010) Novel mechanism of signaling by CD28. Immunol Lett 129: 1-6.

117. Harley CB (1991) Telomere loss: mitotic clock or genetic time bomb? Mutat Res 256: 271-82.

118. O’Bryan JM, Woda M, Co M, Mathew A, Rothman AL (2013) Telomere length dynamics in human memory T cells specific for viruses causing acute or latent infections. Immun Ageing 10: 37.

119. Rizzo LB, Do Prado CH, Grassi-Oliveira R, Wieck A, Correa BL, et al. (2013) Immunosenescence is associated with human cytomegalovirus and shortened telomeres in type I bipolar disorder. Bipolar Disord 15: 832-8.

120. van de Berg PJ, Griffiths SJ, Yong SL, Macaulay R, et al. (2010) Cytomegalovirus infection reduces telomere length of the circulating T cell pool. J Immunol 184: $3417-23$.

121. Pommier JP, Gauthier L, Livartowski J, Galanaud P, Boué F, et al. (1997) Immunosenescence in HIV pathogenesis. Virology 231 : 148-54.

122. Wikby A, Johansson B, Olsson J, Löfgren S, Nilsson B-O, et al. (2002) Expansions of peripheral blood CD8 T-lymphocyte subpopulations and an association with cytomegalovirus seropositivity in the elderly: the Swedish NONA immune study. Exp Gerontol 37: 445-53.

123. Wikby A, Ferguson F, Forsey R, Thompson J, Strindhall J, et al. (2005) An immune risk phenotype, cognitive impairment, and survival in very late life: impact of allostatic load in Swedish octogenarian and nonagenarian humans. J Gerontol A Biol Sci Med Sci 60: 556-65.

124. Strindhall J, Skog M, Ernerudh J, Bengner M, Löfgren S, et al. (2013) The inverted CD4/CD8 ratio and associated parameters in 66-year-old individuals: the Swedish HEXA immune study. Age (Dordr) 35: 985-91.

125. Vallejo AN (2011) Immunological hurdles of ageing: indispensable research of the human model. Ageing Res Rev 10: $315-8$.

126. Luck S, Sharland M (2009) Congenital cytomegalovirus: new progress in an old disease. Paediatr Child Health 19: 178-84.

127. Dorshkind K, Montecino-Rodriguez E, Signer RA (2009) The ageing immune system: is it ever too old to become young again? Nat Rev Immunol 9: 57-62.

128. Russ BE, Prier JE, Rao S, Turner SJ (2013) T cell immunity as a tool for studying epigenetic regulation of cellular differentiation. Front Genet 4: 218.

129. O’Hara GA, Welten SPM, Klenerman P, Arens R (2012) Memory T cell inflation: understanding cause and effect. Trends Immunol 33: 84-90.

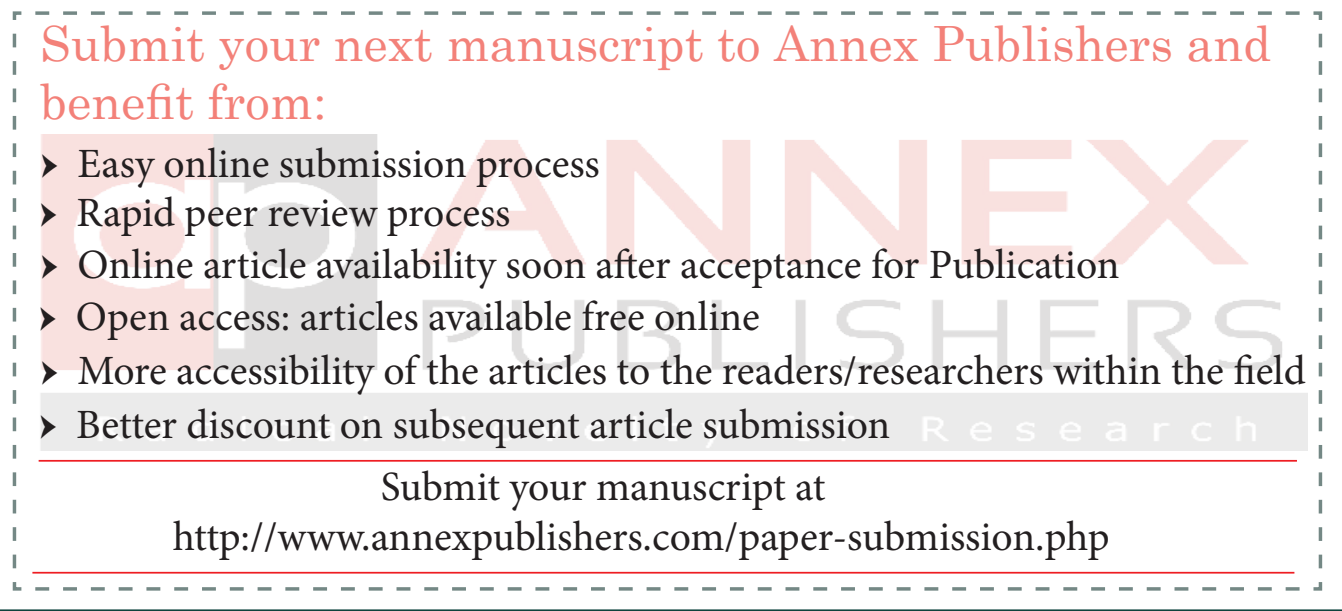

